\title{
Alternating hemiplegia of childhood and rapid-onset dystonia-parkinsonism are both ATP1A3-related disorders
}

\author{
Hendrik Rosewich ${ }^{1 *}$, Holger Thiele ${ }^{2}$, Andreas Ohlenbusch ${ }^{1}$, Ulrike Maschke ${ }^{3}$, Peter Frommolt ${ }^{2}$, Peter Nürnberg ${ }^{2}$, \\ Knut Brockmann ${ }^{4}$, Jutta Gärtner ${ }^{1}$
}

From 50th Workshop for Pediatric Research

Gottingen, Germany. 20-21 March 2014

Alternating hemiplegia of childhood (AHC) was first described as a distinctive disease in 1971 [1]. The disease is characterised by early-onset episodes of hemiplegia, dystonia, numerous paroxysmal symptoms, and developmental impairment [2]. Almost all cases of AHC are sporadic.

To identify de-novo mutations associated with this disease 40 clinically well-characterized patients were recruited from September 2004 till April 2013. Wholeexome sequencing was performed in three proband-parent trios. Informative genes were evaluated in the 37 remaining patients and $A T P 1 A 3$ emerged as the gene associated with AHC [3]. Interestingly, this gene was already known to be associated with another movement disorder with later onset namely rapid-onset dystonia-parkinsonism (RDP) [4]. We then thoroughly analysed clinical and molecular findings of AHC and RDP to evaluate the phenotypic and genotypic spectrum. In addition, we started to analyse the functional consequences of the encoded $\mathrm{Na}^{+}, \mathrm{K}^{+}$alpha 3 subunit for different ATP1A3 mutations associated with either AHC or RDP applying cell survival assays and two-electrode voltage clamp techniques.

39 of 40 patients with a characteristic AHC/RDP phenotype displayed a de-novo mutation in ATP1A3. Our study first showed that AHC and RDP are not two distinct diseases but rather constitute a clinical continuum of one disorder with $\mathrm{AHC}$ at the severe end of the spectrum and RDP as a milder variant. Clinically overlapping features are abrupt onset of triggered dystonic episodes, a rostrocaudal gradient of involvement as well as brainstem dysfunction; clearly differentiating characteristics are fixed dystonia in RDP and episodic hemiplegia in AHC.

'Department of Paediatrics and Paediatric Neurology, University Medical Center Göttingen, Georg August University Göttingen, Göttingen, Germany Full list of author information is available at the end of the article
Further, mutations affecting functional and transmembrane protein domains tend to be associated with an AHC phenotype and the majority of ATP1A3 mutations are located in only four exons [5]. To further elucidate the pathomechanisms of ATP1A3 related disorders in vitro studies on selected mutations are ongoing.

\section{Authors' details \\ 'Department of Paediatrics and Paediatric Neurology, University Medical Center Göttingen, Georg August University Göttingen, Göttingen, Germany. ${ }^{2}$ Cologne Center for Genomics, University of Cologne, Cologne, Germany. ${ }^{3}$ Catholic Hospital St Johann Nepomuk, Erfurt, Germany. ${ }^{4}$ Department of Pediatrics and Adolescent Medicine, University Medical Center Göttingen, Georg August University Göttingen, Göttingen, Germany.}

Published: 11 September 2014

References

1. Verret S, Steele JC: Alternating hemiplegia in childhood: a report of eight patients with complicated migraine beginning in infancy. Pediatrics 1971, 47(4):675-80.

2. Bourgeois M, Aicardi J, Goutieres F: Alternating hemiplegia of childhood. J Pediatr 1993, 122(5 Pt 1):673-9.

3. Rosewich $\mathrm{H}$, Thiele $\mathrm{H}$, Ohlenbusch $\mathrm{A}$, Maschke $U$, Altmuller J, Frommolt $\mathrm{P}$, et al: Heterozygous de-novo mutations in ATP1A3 in patients with alternating hemiplegia of childhood: a whole-exome sequencing geneidentification study. Lancet Neurol 2012, 11(9):764-73.

4. de Carvalho Aguiar P, Sweadner KJ, Penniston JT, Zaremba J, Liu L, Caton $\mathrm{M}$, et al: Mutations in the $\mathrm{Na}+\mathrm{K}+-\mathrm{ATPase}$ alpha3 gene ATP1A3 are associated with rapid-onset dystonia parkinsonism. Neuron 2004, 43(2):169-75.

5. Rosewich H, Ohlenbusch A, Huppke P, Schlotwa L, Baethmann M, Carrilho I, Fiori S, Lourenço CM, Sawyer S, Steinfeld R, Gärtner J, Brockmann K: Neurology 2014.

doi:10.1186/2194-7791-1-S1-A15

Cite this article as: Rosewich et al:: Alternating hemiplegia of childhood and rapid-onset dystonia-parkinsonism are both ATP1A3-related disorders. Molecular and Cellular Pediatrics 2014 1(Suppl 1):A15.

\section{SpringerOpen ${ }^{\circ}$}

(C) 2014 Rosewich et al; licensee Springer This is an Open Access article distributed under the terms of the Creative Commons Attribution License (http://creativecommons.org/licenses/by/2.0), which permits unrestricted use, distribution, and reproduction in any medium, provided the original work is properly cited. 